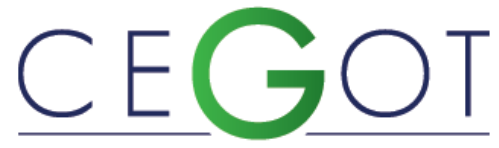

Centro de Estudos de Geografia e Ordenamento do Território
Geografia e Ordenamento do Território, Revista Eletrónica Centro de Estudos de Geografia e Ordenamento do Território http://cegot.org ISSN: 2182-1267

\title{
Fragmentación de las estructuras ecosistémicas en el periurbano de Villa María, Córdoba,
}

\section{Argentina}

\author{
Fragmentação das novas estruturas do ecossistema no periurbano, Córdoba, Argentina
}

Fragmentation of the new ecosystem structures in the periurban area, Córdoba, Argentina

Referência: Guzmán, Leticia Ana; Zulaica, M. Laura; Mizdraje, Dafne (2021). Fragmentación de las estructuras ecosistémicas en el periurbano de Villa María, Córdoba, Argentina. Revista de Geografia e Ordenamento do Território (GOT), n. 21 (Junho). Centro de Estudos de Geografia e Ordenamento do Território, p. 139-158, dx.doi.org/ 10.17127/got/2021.21.006

\section{RESUMEN}

Los cambios de uso del suelo han ido en detrimento de los ecosistemas naturales. En Argentina la ecorregión Espinal es una de las más afectadas quedando solo unos pocos relictos. La provincia de Córdoba es una de las mayores productoras agrícolas, lo que llevó a la modificación de los ecosistemas naturales, perdiendo los servicios ambientales que estos proveen. Esto sucede en la ciudad de Villa María y especialmente en su territorio periurbano. La identificación y análisis de la fragmentación de las estructuras ecosistémicas en este periurbano, aporta una forma diferente de identificación de las nuevas estructuras ecosistémicas para ser considerados en el ordenamiento territorial de las ciudades medianas o pequeñas. Se identificaron seis estructuras ecosistémicas (parches): Ecosistemas Residuales, Neoecosistemas, Neosuelos, Neohumedales, Neoredes de Escurrimiento Superficial y Geofagia. Su procesamiento a través de un Sistema de Información Geográfica permitió mapear los resultados de relevamiento e identificar los servicios ambientales que 
éstas brindan. El trabajo de campo permitió evidenciar la riqueza y diversidad presente; sin embargo, la distancia y tamaño de los mismos denota la vulnerabilidad de los parches. La importancia que revisten las estructuras en cuanto a la provisión de servicios demanda la necesidad de consolidar estrategias políticas en la gestión municipal tendientes a la protección de los parches.

Palabras claves: Periurbano; Ordenamiento territorial; Ecología del paisaje, Ambiente.

\section{RESUMO}

Mudanças no uso da terra têm prejudicado os ecossistemas naturais. Na Argentina, a ecorregião Espinal é uma das mais afetadas, restando apenas algumas relíquias. A província de Córdoba é um dos maiores produtores agrícolas, o que levou à modificação dos ecossistemas naturais, perdendo os serviços ambientais por eles prestados. Isso acontece na cidade de Villa María e especialmente em seu território periurbano. A identificação e análise da fragmentação das estruturas dos ecossistemas nesta área periurbana oferece uma forma diferente de identificar as novas estruturas dos ecossistemas a serem consideradas no planejamento territorial de cidades médias ou pequenas. Seis estruturas ecossistêmicas (manchas) foram identificadas: Ecossistemas Residuais, Neoecossistemas, Neossolos, Neohumedales, Neoredes de Escoamento de Superfície e Geofagia. O seu processamento através de um Sistema de Informação Geográfica permitiu mapear os resultados dos levantamentos e identificar os serviços ambientais que prestam. $O$ trabalho de campo permitiu mostrar a riqueza e diversidade presente; no entanto, sua distância e tamanho denotam a vulnerabilidade dos patches. A importância das estruturas em termos de prestação de serviços exige a necessidade de consolidação de estratégias políticas de gestão municipal voltadas para a proteção das manchas.

Palavras-chave: Periurban area; Ordenamento territorial; Ecologia da paisagem, meio ambiente.

\section{ABSTRACT}

Changes in land use have been detrimental to natural ecosystems. In Argentina, the Espinal ecoregion is one of the most affected, with only a few relics remaining. The province of Córdoba is one of the largest agricultural producers, which led to the modification of natural ecosystems, losing the environmental services they provide. This happens in the city of Villa María and especially in its peri-urban territory. The identification and analysis of the fragmentation of the ecosystem structures in this peri-urban area provide a different way of identifying the new ecosystem structures to be considered in the territorial planning of medium or small cities. Six ecosystemic structures (patches) were identified: Residual Ecosystems, Neoecosystems, Neosols, Neohumedales, Surface Runoff Neoredes, and Geophagy. It's processing through a Geographic Information System allowed mapping the survey results and identifying the environmental services that they provide. The fieldwork allowed to show the richness and diversity present; however, their distance and size denote the vulnerability of the patches. The importance of the structures in terms of the provision of services demands the need to consolidate political strategies in municipal management aimed at protecting the patches.

Keywords: Periurban; Territorial planning; Landscape ecology, Environment. 


\section{Introducción}

Los procesos de urbanización han alcanzado una velocidad sin precedentes. En América Latina y el Caribe, entre 1960 y 2015, la población urbana aumentó de 44\% a 78\% (BID, 2016). La urbanización acelerada ha derivado en problemas sociales y ambientales, que se manifiestan especialmente en áreas complejas y dinámicas, denominadas periurbanas.

González Urruela (1987) realiza un análisis de los diversos abordajes de las áreas periurbanas, en el cual establece que, por su variedad y complejidad, se han llamado rururbano, suburbano, zona de influencia o transición. El autor expresa que el periurbano, es un espacio diverso y es necesario el uso de diferentes términos para que se contemplen las características específicas. Por otra parte, Di Pace y Caride Bartrons (2012), Zaar (2011), Zulaica (2010) y Morello y Matteucci (2001), señalan que en el periurbano los subsistemas son diversos y están constituidos por canteras, cría intensiva de animales (pollos y cerdos), basurales a cielo abierto, áreas de depósito de escombros, centros de disposición de residuos, loteos con pequeñas viviendas, porciones destinadas a cultivos, cortaderos de ladrillos, suelos decapitados, hortícolas (bajo cubierta y en suelo) y parches fragmentados de vegetación natural y seminatural.

La conformación del periurbano, implica necesariamente cambios en los usos del suelo que suelen generar impactos a través de modificaciones, en las condiciones de vida, por las características intrínsecas del tipo, manejo, métodos o tecnologías de producción, desconocimiento de dinámicas naturales o por ausencia de estudios científicos que demuestren y/o avalen la capacidad y la vulnerabilidad de los ecosistemas (Barsky, 2005). Estas modificaciones originan nuevos y diferentes paisajes que transforman las características y capacidades del sistema ecológico natural (Guimarães, 1998). En este sentido, Barsky (2005) expresa que la identificación de las problemáticas en los países latinos sobre la ocupación del suelo en las zonas periféricas presenta una gran heterogeneidad y profundos problemas sociales, ambientales, entre otros, con un crecimiento acelerado de la población, las urbanizaciones y los conflictos. El autor manifiesta que las zonas periurbanas son las de mayor fragilidad ecológica por las actividades intensivas que en ella se desarrollan, con una gran presión antrópica y las 
describe como zonas en situación crítica a nivel planetario; además, postula que los espacios agrícolas y naturales aledaños a las ciudades son los de mayor necesidad de protección.

Estas áreas, frecuentemente carecen de programas de desarrollo sostenidos en políticas e instrumentos para el Ordenamiento Territorial (OT), o bien no se han aplicado adecuadamente. De acuerdo con Gómez Orea y Gómez Villarino (2013), el OT define la estructura espacial o marco físico (forma de utilización del suelo, redes formadas por núcleos de población y por canales que conectan el conjunto) hacia el futuro, en el que se organizan actividades favorecidas por políticas sociales, económicas, culturales y ambientales. Asimismo, regula el comportamiento de los agentes socioeconómicos para alcanzar un desarrollo equitativo, equilibrado y sostenible. Según Massiris Cabeza (2005), se trata de un proceso que pretende configurar, en el largo plazo, una organización del uso y ocupación del territorio acorde con sus potencialidades y limitaciones considerando las expectativas y las aspiraciones de la población. Es así que el OT en las ciudades y sus territorios periurbanos es un proceso complejo que varía en función a las características intrínsecas de cada zona, siendo aún más complejo en las áreas periurbanas, que cuentan con una mayor dinámica de transformación que otros espacios.

Según Breuste, Haase \& Elmqvist (2013) las ciudades son una gran amenaza para la biodiversidad e incrementan la homogeneización de la fauna y la flora, siendo de gran importancia que los municipios desarrollen estrategias para la coexistencia funcional entre ciudades y la naturaleza.

En la localidad de Villa María, provincia de Córdoba, Argentina, se delimitó el espacio periurbano y, en función de los usos establecidos por Morello y Matteucci (2001), se evidencia la existencia de procesos de dispersión productiva, fragmentación de los ecosistemas, episodios de inundaciones y el despliegue de diferentes procesos de antropización que afectan la sustentabilidad del periurbano, por lo que resulta necesaria su consideración en el OT. Asimismo, los parches que presentan vegetación nativa aportan servicios ambientales, por lo que juegan un rol clave. En este sentido, los servicios ambientales pueden definirse como procesos ecosistémicos que regulan las condiciones del ambiente en los que los humanos habitan, como la regulación del clima o de la erosión, siendo beneficios directa 0 indirectos para las sociedades (Millennium Ecosystem Assessment, 2005). 
Los servicios ambientales están presentes en los espacios periurbanos y se definen como los beneficios que las personas y la sociedad obtienen de los ecosistemas para su calidad de vida. Dentro de estos los servicios de regulación en regiones de baja pendiente son fundamentales ya que la absorción del agua de las lluvias es fundamental en las ciudades donde la impermeabilización del suelo es alta. Asimismo, la regulación de la calidad del aire provista por los fragmentos de vegetación nativa que quedan en los espacios periurbanos. Los patrones de uso del suelo como las dinámicas de transformación de los mismos en las ciudades están altamente relacionados con las condiciones culturales y ambientales que afectan directamente a los servicios ambientales (Breuste, Haase \& Elmqvist, 2013). La pérdida de los ambientes naturales y seminaturales, junto a la fragmentación territorial incrementa la pérdida de los servicios ambientales, ya que estos en principio se reducen por la reducción de los fragmentos y por el incremento de los bordes de contorno con otros usos, reduciendo la capacidad de regeneración.

En función de la importancia de estos fragmentos, resulta importante estudiar aquellos parches (Guzmán, 2019) de vegetación nativa o ecosistemas residuales y aquellos con vegetación exótica y nativa o neoecosistemas, dentro del periurbano de Villa María, con la finalidad de evaluar su estado de protección actual. Ello permitirá conocer si es posible garantizar la provisión de servicios ambientales de regulación y, en algunos casos, culturales.

\section{Las transformaciones territoriales en Argentina}

La población urbana de Argentina estimada por el INDEC para 2020 asciende a unos 42 millones de habitantes que conforman el $92,5 \%$ de los habitantes del país. En virtud de ello, Argentina se encuentra entre las naciones más urbanizadas del mundo pero con una economía que desde el siglo XX se focaliza principalmente en las exportaciones agrícolas (Bran, Gaitán y Wilson, 2017; Morello y Matteucci, 2000).

Estudios antecedentes demuestran que este modelo productivo ha impactado fuertemente en la calidad ambiental del territorio (Pengue, 2009) a lo largo del tiempo. En el país, son varias las investigaciones que estudian la calidad ambiental desde los preceptos para el desarrollo sustentable, entendiendo que la misma conduce a satisfacer las necesidades del 
presente sin comprometer la capacidad de las generaciones futuras para cubrir las propias. Este concepto plantea serios desafíos para ser alcanzados, por un lado el lograr el desarrollo y por el otro, es que en el intento no se comprometa severa e irreversiblemente las capacidades de los sistemas naturales.

Por otra parte, las características ecológicas del país están representadas por 18 ecorregiones (Burkart et al., 1999), que incluyen grandes espacios territoriales donde la fisonomía del paisaje es relativamente homogénea y existen diferentes comunidades naturales que tienen en común un gran número de especies y condiciones ambientales semejantes. Una de dichas ecorregiones es El Espinal, que está presente en las provincias de Entre Ríos, Santa Fe, Córdoba, Buenos Aires y La Pampa. Esta ecorregión cuenta con suelos de buena calidad para el desarrollo de actividades agrícolas, que ha generado un proceso de transformación de los suelos boscosos hacia suelos agrícolas y ganaderos desde comienzos del siglo XX. La expansión de la frontera agrícola es responsable de la reducción de las masas boscosas, quedando escasos manchones relictuales en una extensa matriz de cultivos anuales, siendo las provincias de Santa Fé y Córdoba las que más han perdido representatividad de esta ecorregión (Zak y Cabido, 2012).

La provincia de Córdoba es una de las mayores productoras agrícolas en Argentina (Ministerio de Agricultura, Ganadería y Pesca de la Nación, 2020), y las definiciones en torno a las políticas ambientales y al Ordenamiento Territorial no han conducido a un desarrollo sustentable de la región. Sin embargo, fue una de las provincias pioneras en contar normativa ambiental específica como es la Ley Provincial № 7.343 de "Principios rectores para la preservación, conservación, defensa y mejoramiento del ambiente" en el año 1985. Esta Ley planteó herramientas de alto potencial; sin embargo sus alcances no se reflejaron en la gestión y el ordenamiento territorial de la Provincia. Por otra parte, a los alcances normativos, se suman las discusiones jurisdiccionales. En ese sentido, Córdoba está dividida políticamente en 26 departamentos y cuenta con más de 500 municipios y comunas (desde 200 hasta más de 500 mil habitantes) sin límites colindantes. Esta situación conlleva a que existan espacios entre municipios que son únicamente de jurisdicción provincial. Esta configuración diversa y también variable en los límites jurisdicciones, repercute en los municipios, como es el caso de Villa María. 
En el año 2008 la provincia ratificó, por intermedio de la Ley № 9.509, la ampliación del radio municipal de la localidad de Villa María, propuesto en la Ordenanza Municipal $\mathrm{N}^{\circ}$ 5.929, resultando en una nueva configuración del municipio que lo lleva de áreas netamente urbanas a urbanas y rurales. A partir de dicha modificación, fueron incorporadas extensas superficies de fuerte impronta rural y productiva a la jurisdicción municipal, generando así un espacio de transición urbano-rural que puede definirse como periurbano. En términos generales, estas áreas periurbanas, son espacios complejos, mixtos, diversos y dinámicos, con una alta tasa de transformación y que reflejan problemas ambientales derivados de esta condición de interfase.

En este contexto, y considerando la importancia de los servicios de regulación aportados por relictos de ecosistemas naturales, el presente trabajo analiza la fragmentación de los ecosistemas periurbanos de Villa María mencionados, producidos por las dinámicas de transformación del uso del suelo en las áreas de interfaz urbano-rural. Esto será de gran relevancia debido a que dichos parches exhiben situaciones de vulnerabilidad ambiental en especial por la escasa pendiente, intensificación de fenómenos asociados con el cambio climático y la transformación de ecosistemas de la ecorregión.

\subsection{El Área de Estudio: periurbano de Villa María}

El área de estudio es en el periurbano de Villa María, localizada entre los meridianos 6314'49,46" a 6310'58,87" de longitud Oeste y los paralelos 3227'43,62" a 3220'56,14" de latitud Sur. Está delimitada por la Autopista Rosario - Córdoba hacia el Noreste y al Este hacia el Suroeste y se ubica en la cuenca media del Río Ctalamochita sobre el margen del mismo colindante a la ciudad de Villa Nueva que está en el otro margen del río, en la provincia de Córdoba Argentina.

Según el Plan Estratégico Territorial Nacional (Ministerio de Planificación Federal, Inversión Pública y Servicios, 2008) la provincia de Córdoba cuenta con una red urbana que cubre aproximadamente toda su superficie. Los principales núcleos urbanos son: Gran Córdoba (con Villa Carlos Paz), Río Cuarto, Villa María y San Francisco, que acumulan el 64\% de la población de la provincia. La ciudad de Villa María cuenta con la mayor población del Departamento General San Martín y es la tercera localidad más grande de la provincia. El 
Centro de Estadísticas de la Municipalidad de Villa María, establece que la localidad cuenta con una proyección de la población al 2018 de 79.351 habitantes dentro de su radio municipal.

El paisaje de tipo Espinal que ocupaba este territorio, desde la constitución de la ciudad hace ya más de 150 años, fue modificado en principio para la producción agrícola ganadera (Rüedi, 2016) y posteriormente por la urbanización, quedando dentro del radio municipal únicamente un $2,94 \%$ de la superficie total del periurbano, que se encuentra de forma dispersa y en pequeñas unidades en todo el territorio (Guzmán, 2019).

Las actividades económicas de la ciudad se dividen entre diferentes rubros que abarcan desde comercios por menores, servicios públicos, educación de diferentes niveles, producción agrícola y ganadera, servicios e industrias, se destacan que la localidad es la cabecera de la cuenca lechera. El periurbano de Villa María presenta una alta diversidad de usos del suelo, en total 18 tipos (Figura 1, Tabla 1), de los cuales la agricultura extensiva representa la mayor superficie del periurbano, seguido por la actividad tambera (Guzmán, 2019).

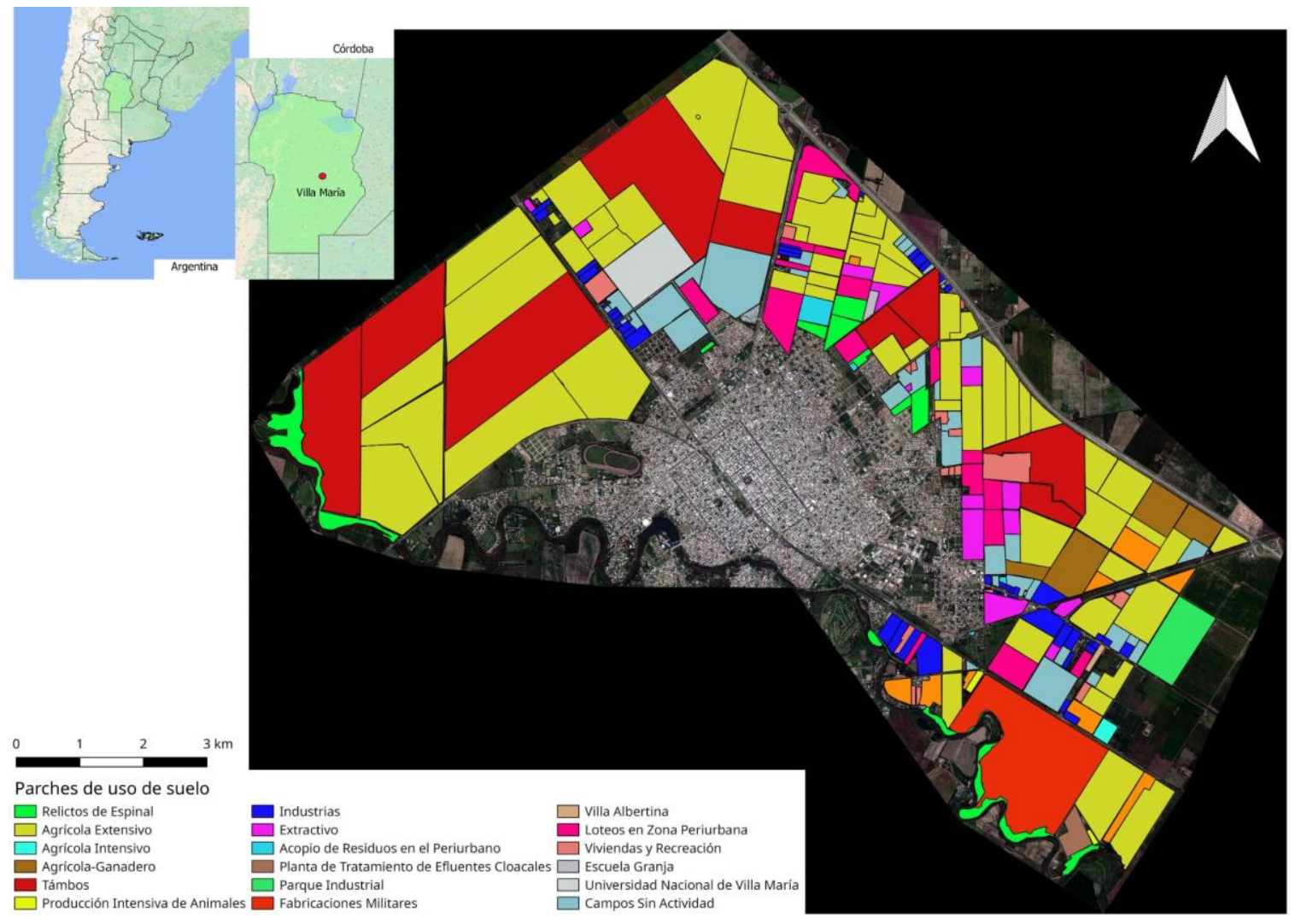

Figura 1. usos del suelo periurbano Villa María, Córdoba, Argentina.

Fuente: Guzmán (2019) 
Tabla 1. Usos del suelo en el periurbano de Villa María

\begin{tabular}{|c|c|}
\hline Tipo de uso de suelo & Características \\
\hline Relicto de Espinal (RE) & $\begin{array}{l}\text { Suelo con predominancia de especies nativas del Espinal, con } \\
\text { una baja o nula modificación, con similar estructura al estado } \\
\text { original. Espacios destinados a la conservación de espacio } \\
\text { natural o especies animales o vegetales. }\end{array}$ \\
\hline Agrícola Extensiva (AE) & Cultivos extensivos, principalmente con siembra de soja y maíz. \\
\hline Agrícola Intensiva (AI) & $\begin{array}{l}\text { Horticultura, fruticultura. Plantaciones diversas y eventualmente } \\
\text { con invernáculos. }\end{array}$ \\
\hline Agrícola-ganadero (AG) & $\begin{array}{l}\text { Campos de producción agrícola con introducción de animales. } \\
\text { Cria, recría y engorde de bovinos. }\end{array}$ \\
\hline Tambo (T) & Cría de bovinos para la producción de leche. \\
\hline Producción intensiva animal (PIA) & Pollo parrillero, conejos y/o cerdos. \\
\hline Industrial (I) & $\begin{array}{l}\text { Instalaciones industriales mixtas distribuidas fuera del Parque } \\
\text { Industrial. }\end{array}$ \\
\hline Extractivo (E) & $\begin{array}{l}\text { Extracción de suelo para producción de ladrillos o que muestran } \\
\text { rastros de haber albergado la actividad extractiva de este tipo. }\end{array}$ \\
\hline $\begin{array}{l}\text { Acopio de Residuos en el Periurbano } \\
\text { (ARP) }\end{array}$ & $\begin{array}{l}\text { Terrenos utilizados para el depósito de residuos de diferentes } \\
\text { tipos, con y sin autorización municipal para esta actividad y que } \\
\text { su permanencia es constante en el tipo. }\end{array}$ \\
\hline $\begin{array}{l}\text { Planta de Tratamiento de Efluentes } \\
\text { Líquidos Cloacales (PTELC) }\end{array}$ & Espacio utilizado para tratamiento de efluentes cloacales. \\
\hline $\begin{array}{l}\text { Parque Industrial y Tecnológico Villa } \\
\text { María (PITVM) }\end{array}$ & $\begin{array}{l}\text { Predio establecido por O.M. N5.907 para la localización de } \\
\text { emprendimientos Industriales. }\end{array}$ \\
\hline Fabricaciones Militares Villa María (FM) & Fábrica de pólvora perteneciente a Fabricaciones Militares. \\
\hline Villa Albertina (VA) & $\begin{array}{l}\text { Barrio establecido en zona industrial censado en el } 2010 \text { aparte } \\
\text { de Villa María. }\end{array}$ \\
\hline Loteos en la zona periurbana (LZP) & $\begin{array}{l}\text { Loteos establecidos fuera de la continuidad urbana con } \\
\text { presencia parcial o no de viviendas. }\end{array}$ \\
\hline Viviendas y Recreación (VR) & Casas-quintas y predios de recreación. \\
\hline Escuela Granja Los Amigos (EG) & $\begin{array}{l}\text { Espacio de uso mixto con fines educativos con uso de } \\
\text { horticultura y ganadería a pequeña escala. }\end{array}$ \\
\hline $\begin{array}{l}\text { Universidad Nacional de Villa María } \\
\text { (UNVM) }\end{array}$ & $\begin{array}{l}\text { Campus de la Universidad Nacional de Villa María, cuenta con } \\
\text { campo agrícola experimental, campo recreativo, módulos de } \\
\text { educación, residencias y pequeño relicto de bosque nativo. }\end{array}$ \\
\hline Campos sin Actividad (CSA) & $\begin{array}{l}\text { Antiguos campos productivos agrícolas, ladrilleras u otros que se } \\
\text { encuentran sin actividad reciente, con presencia de vegetación } \\
\text { rala o exótica, así como parches con neohumedales. }\end{array}$ \\
\hline
\end{tabular}

Fuente: Guzmán (2019) 
El área periurbana de Villa María presenta características sociales y de producción heterogéneas, donde los procesos de transformación están dados por factores endógenos, propios del sistema complejo de la localidad y factores exógenos que responden a políticas nacionales y provinciales sumado a condiciones macroeconómicas. Por otra parte, los actores intervinientes en el territorio periurbano fueron agrupados en 13 categorías en función a las actividades que desarrollan en este espacio (Guzmán, 2019).

\section{Metodología}

En el análisis de la fragmentación de los ecosistemas periurbanos de Villa María mencionados, se adoptan en primer lugar las conceptualizaciones de Morello y Matteucci (2001) quienes sostienen que cada porción de la superficie es el resultado de la evolución de procesos geomorfológicos, del clima, el tiempo, donde participaron materiales geológicos de base. La interpretación espacial del territorio y los usos se determinan a partir de unidades de paisaje mapeables, mayoritariamente homogéneas en relación a la configuración vegetal cuyos límites se establecieron por el cambio en una o más de sus características (Naveh, Lieberman, Sarmiento, Ghesa y León, 2001). Los parches se definen como una superficie que se diferencia de las áreas contiguas, pudiendo variar en tamaño, forma, tipo, bordes, pueden ser de igual denominación, colindantes y diferenciarse por su gestión o pertenencia (Guzmán, 2019; Muñoz, 2010; Zulaica, 2010; Cendrero et al., 2002; Aramburu, Escribano y Rubio, 2001; Matteucci, 1998).

El trabajo con herramientas de procesamiento de imágenes satelitales aporta una alternativa para el abordaje del territorio donde se pueden incluir las diferentes disciplinas, conformando una cartografía integral y dinámica (Portiansky, 2013). Asimismo, se ha transformado en una práctica indispensable para el ordenamiento territorial, ya que su uso permite lecturas cuantitativas y cualitativas relacionando factores que no podrían ser abordados sin la espacialidad debida (Buzai, Baxendale, Humacata y Principi, 2016). Para este trabajo se utilizó la herramienta de geoproceso libre Qgis 3.12 y se trabajó con los datos satelitales de imágenes de google satelital de septiembre de 2020 donde se confeccionaron capas vectoriales surgidas del relevamiento a campo de los parches con nuevas estructuras ecosistémicas identificadas a campo. Para la definicipio de los parches, 
se evaluó la presencia fisonomía vegetal de tipo arbórea con estratos vegetales, que representen al Espinal, los seminaturales integrado con especies arbóreas exóticas de tipo ornamentales o funcionales, así como las estructuras que modifican el relieve y la construcción del suelo, las cuales fueron establecidas por Morello y Matteucci (2001) en seis estructuras ecológicas. El relevamiento a campo se realizó con GPS, registro fotográfico e identificación de especies vegetales presentes. Los datos relevados georeferenciados permiten identificar la distribución y fragmentación de los mismos. Asimismo, se tomaron los principios de la teoría insular y efecto de borde donde se buscó identificar la superficie del parche y distribución, especies vegetales presentes y la relación de perímetro/superficie para determinar los riesgos que presenta la fragmentación espacial de los parches (Santos y Tellería, 2006).

\section{Resultados y Discusión}

O El periurbano de Villa María para el 2020 representa el $77 \%$ de la superficie de la localidad. Este valor fue ajustado sobre la base del establecido por Guzmán, Castro, Becker, Furlán y Rodríguez (2016) ya que se incorporaron al periurbano espacios como el hipódromo y loteos no consolidados, respondiendo a los objetivos del presente trabajo. En este sentido, la diferencia y el aumento de la superficie del periurbano no representa un crecimiento del área, sino la evidencia de la flexibilidad del concepto y su aplicación en la delimitación en función de los objetivos propuestos.

Al interior del periurbano de Villa María se identificaron como especies representativas de la ecorregión árboles, arbustos, hervaceas y epífitas como ser: Garabato (Acacia praecox)(1), Algarrobo negro (Prosopis nigra), Duraznillo blanco (Solanum argentnum) (2), Duraznillo negro (Cestrum parqui L'Hér), Chañar (Geoffroea decorticans), Piquillin (Condalia microphylla), Espinillo (Acacia caven)(4), Tala (Celtis ehrenbergiana)(5), Sombra de toro (Jodina rhombifolia), Palan palan (Nicotiana glauca), Palo amarillo (Aloysia gratissima), Penca (Opuntia ficus-indica), Campanilla (Ipomoea purpurea), Santa Lucía (Commelina erecta), Clavel del aire (Tillandsia pedicellata), Chaguar (Deuterocohnia longipetala)(6), Pichana (Senna aphylla), Amor seco (Bidens pilosa), Barba de viejo (Clematis montevidensisi)(7), Maitén (Maytenus), Paja brava (Stipa ichu) (8), Algarrobo blanco 
(Prosopis Alba)(9) (Figura №2). De las especies exóticas presentes se encuentran el eucaliptus (Eucalyptus), moras (morus), ligustro (Ligustrum), fresno (Fraxinus), abedul (Bétula))(10), álamo (Salicaceae), paraíso (Elaeagnus angustifolia)(10), siempreverde (Myoporum), entre otras (Figura 2).

Los parches definidos a partir del procesamiento de los datos vectoriales y las imágenes, brindan servicios de regulación tales como control de la erosión, regulación hídrica, provisión de nutrientes y servicios culturales entre los que se destacan las cortinas forestales; y funciones recreativas y ecológicas, por ejemplo aquellas que se encuentran en las riberas del río.

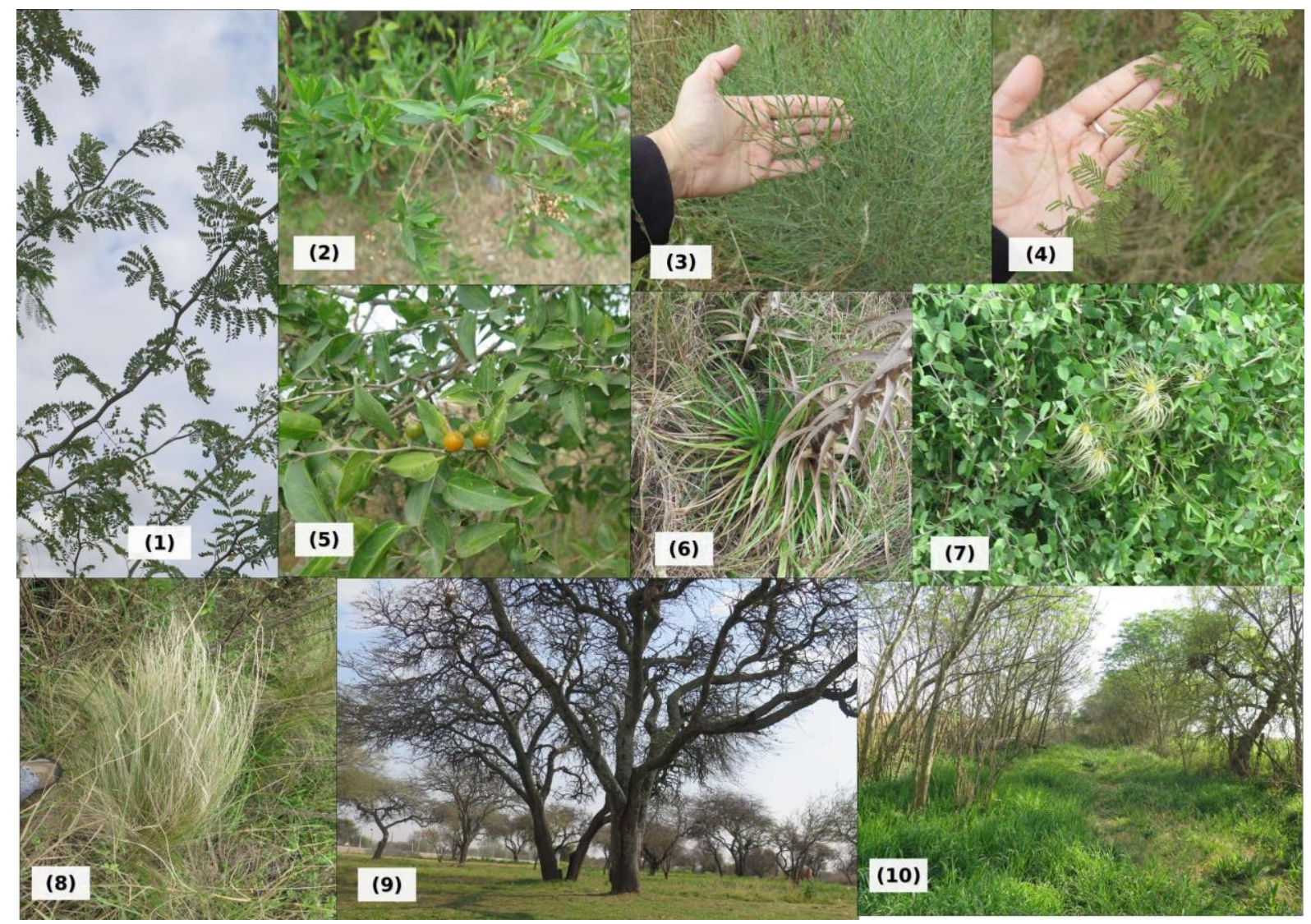

Figura 2. Especies nativas del periurbano de Villa María.

Fuente: Elaboración propia Imagenes 2014-2020.

El periurbano de Villa María presenta estructuras ecosistémicas que son el resultado de la interacción entre la sociedad y el entorno coincidiendo con lo expresado por Morello y Matteucci (2001). Una de estas estructuras centrales son los "Ecosistemas Residuales", es decir, espacios de ecosistemas naturales o seminaturales incluidos en la matriz del 
periurbano en los cuales la composición de las especies vegetales, la dominancia y estructura vertical son similares a las originales. Estos fueron identificados en el periurbano de Villa María como Relictos de Espinal con estructuras originarias, y el bosque de ribera en los márgenes del río Ctalamochita, con fisonomía vegetal propia del Espinal, con baja modificación y presencia de pocas especies exóticas (Figura 3). Además, se encontraron elementos bióticos pertenecientes a los sistemas naturales originales pero con dominio de especies exóticas naturalizadas o invasoras definidas como "Neoecosistemas"; así como también, “Neohumedales" generados por las acciones antrópicas (Morello y Matteucci, 2001) (Figura 3). Los neoecosistemas están presentes en campos sin actividad, campos agrícolas, tambos y en bordes de caminos rurales, con diferentes grados de intervención de la vegetación nativa y dominio de exóticas. Por su parte, los neohumedales están representados por "las lagunas de retardo", que cumplen la función de acumular el agua en los periodos de excesos hídricos producidos por las precipitaciones, y se identificaron tres sitios que reflejan estas características. Una de dichas lagunas es "La Cava", el predio más extenso (10,2 ha), el cual se generó por la extracción de tierra que se utilizó para la construcción de la Autovía Córdoba - Rosario. En esta laguna de retardo, una zona es utilizada para la deposición de residuos clandestino por parte de particulares y depósito de escombros por parte del municipio; además, es importante destacar que colindante a la misma se realizó un loteo en el 2013 cuyo escurrimiento superficial desemboca en esta laguna. Otra de las lagunas de retardo, actualmente activa, es la ubicada en la calle Salta, la misma se construyó para dicha finalidad, está cercada y presenta principios de remoción de suelo en los laterales por el escurrimiento superficial. La tercera laguna se encuentra dentro de la Reserva Urbana "El Algarrobal" donde ocupa más del $50 \%$ de la superficie de la reserva.

Por otra parte, otra de las estructuras que se identificaron fueron los "Neoredes de escurrimiento superficial" (Morello y Matteucci, 2001) que son modificaciones de variados orígenes e intensidades sobre casi todos los componentes de la red hidrográfica. Se estableció la presencia de esta categoría relacionada a las modificaciones en el uso del suelo, como por ejemplo "Los Cardenales", reciente loteo del periurbano que se emplazó en un antiguo campo sin uso que anteriormente al 2013 se utilizaba para actividad agrícola y posteriormente a los movimientos de tierra para consolidar el loteo en 2016, se observaron 
hundimientos generados por escurrimiento superficial. Este loteo se encuentra en un bajo, respecto a los terrenos colindantes y el escurrimiento superficial va en dirección Noreste. Otro aspecto relevante de las Neoredes de escurrimiento, son los desagües pluviales, los cuales se establecieron en el "Plan Director de Desagües Pluviales", generado por la municipalidad de la ciudad de Villa María en conjunto con la Secretaría de Recursos Hídricos de la Provincia y fue aprobado por Ordenanza Municipal № 7.193 en septiembre de 2017. En dicho marco se planificaron seis sitios de retardo (neohumedales de los cuales solo están consolidados los anteriormente mencionados) y canales de desagüe que atraviesan el periurbano, algunos de los cuales ya se encuentran realizados, como es el caso del canal que se ubica paralelo a la calle Buenos Aires, arteria principal que divide dos zonas en el periurbano. El otro desagüe, atraviesa el periurbano por un camino rural y marca el límite interno de una de las zonas del periurbano. Ambos son desagües descubiertos y recogen gran parte del escurrimiento de la región urbana periférica que desemboca fuera del periurbano (Figura 3).

Los "Neosuelos" que son nuevas formas de soporte edáfico constituido con basura y depósitos de escombros ubicados donde se realizaban actividades de extracción de suelo (Morello y Matteucci, 2001); además, la intervención antrópica o presencia de ladrillos, escombros o basura se ha identificado en varios lugares del periurbano como en los casos de los Basurales Clandestinos (Figura 3).

En el periurbano se observa actividad extractiva del suelo denominada por Morello y Matteucci (2001) como “Geofagia”, con decapitación del mismo, presencia de excavaciones, rellenos en los laterales que modifican la energía y amplitud del relieve. Estas nuevas estructuras ecosistémicas están asociadas principalmente a la extracción de suelo para la construcción de ladrillos en el periurbano de Villa María. La actividad contaba con 15 parches en el 2003 dentro del radio municipal y solo el 6,9\% se encontraba fuera del mismo, mientras que en el 2017 el 68,29\% de las ladrilleras se encontraban fuera del radio municipal y en 2020, solo 4 parches ladrilleros quedan dentro del radio municipal. Estos procesos son importantes ya que sus dinámicas tanto físico ambientales como sociales son complejas. En el periurbano de Villa María el $20 \%$ de las superficies que fueron ocupadas por ladrilleras se utilizaron para loteos nuevos (Figura 3). 


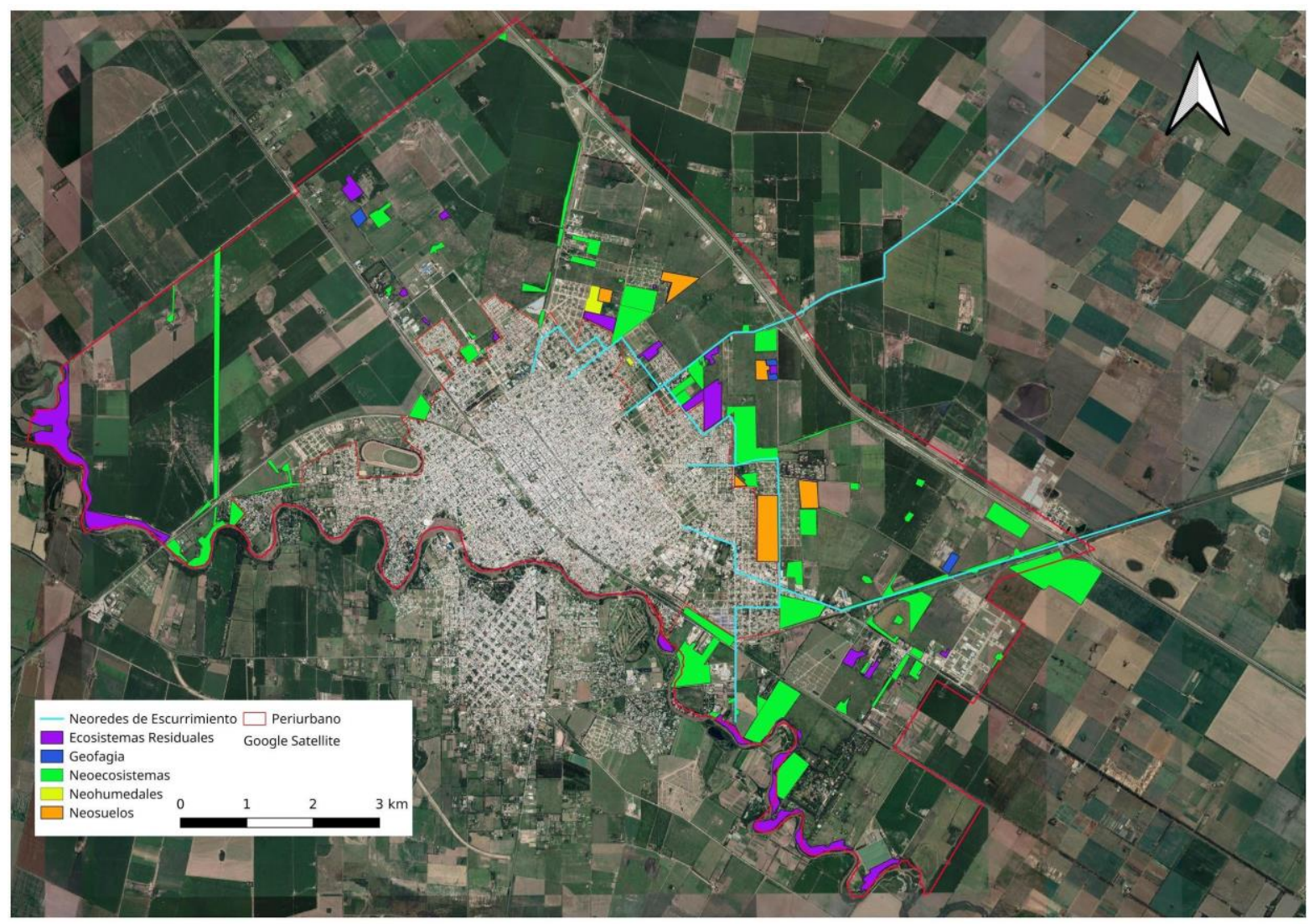

Figura 3. Estructuras ecosistémicas

Fuente: Elaboración propia

Como se desprende de lo anterior, en el periurbano de Villa María los neoecosistemas son los predominantes; sin embargo, los tamaños de los parches y en ocasiones la distancia entre ellos los transforman en islas. Los ecosistemas residuales poseen una representación significativa en la ribera del río, pero su conectividad con los pequeños parches de Espinal son nulos, y esto dificulta su funciones como corredor. El riesgo de la fragmentación es principalmente la pérdida de biodiversidad, ya que los bordes y los tamaños de los ecosistemas residuales no son los los óptimos para su enriquecimiento, poniendo así en peligro los servicios ambientales que éstos proveen. Sumado a la fragmentación y a la distribución, los usos del suelo colindante no presentan características que enriquezcan o acompañen el desarrollo de estos dos tipos de estructuras, siendo lamentablemente la urbanización y la actividad agrícola extensiva con uso de agroquímicos las mayores amenazas. Asimismo, los ecosistemas residuales que se encuentran colindantes al río cumplen funciones reguladoras esenciales que deben tener estructuras de conservación. 
Los neohumedales, por su parte, podrían incrementar el servicio de regulación para la conservación de la biodiversidad a través del aumento de ciertas especies como por ejemplo la avifauna y plantas acuáticas; sin embargo, por ser de características temporales la presencia de agua y no contar con un plan de manejo de las mismas, se utiliza como depósito de basura clandestina, con potenciales efectos sobre la salud ambiental. Lo mismo sucede con las neoredes de escurrimiento, aquellas que son canales de tierra abiertos no poseen suficiente mantenimiento, concentrando residuos en su lecho.

De los seis parches de neosuelos que se generaron por el relleno de antiguas ladrilleras actualmente en desuso, los dos de mayor superficie se encuentran destinados a nuevos loteos de viviendas. Por otra parte, las escasas ladrilleras que todavía persisten dentro del radio municipal, están asociadas a neosuelos, ecosistemas residuales y/o neoecosistemas. Aquí predominan los servicios culturales asociados a usos urbano-residenciales.

Las dificultades evidenciadas tanto en la gestión y el mantenimiento, como en el monitoreo y remediación de los neosuelos y de las neoredes de escurrimiento, afectan directamente a la salud ambiental, ya sea por la quema de residuos que tiene lugar en los basurales clandestinos que se generan junto a los neosuelos y a los límites de los ecosistemas residuales. La salud ambiental de los espacios periurbanos (Ortíz Moreno y Vieyra Medrano, 2018; Allen, Dávila y Hofmann, 2005) puede perjudicar o mejorar la calidad ambiental para los habitantes, de ahí su importancia en la gestión municipal como elementos que vinculan los aspectos ambientales y sociales.

Un primer indicio de esta vinculación fue la sanción de 2017 de la Ordenanza Municipal № 7.209, donde se incorporan los usos periurbanos a la dinámica urbana. Este antecedente crea el "Área de Ruralidad Urbana", la cual se encargaría de analizar los pasivos ambientales y evaluar los servicios ambientales, entre otras funciones. Sin embargo, la ausente consolidación del área no alcanza a dar respuesta a las problemáticas emergentes en estas estructuras periurbanas.

La distribución espacial y la escasa superficie, con un alto borde de las estructuras ecosistémicas denotan una alta fragmentación territorial, con una mayor cantidad de neoecosistemas. Estas estructuras cuentan con menor diversidad de especies, predominando las exóticas e invasoras, lo cual tiende a reducir el intercambio de semillas y 
circulación de aves, insectos y mamíferos con otros parches. Asimismo, la distribución de estos parches y la distancia entre ellos los posiciona como islas en medio de usos productivos o urbanos, siendo el efecto de borde una problemática relevante ya que la aplicación de agroquímicos en los campos aledaños a los parches reduce la posibilidad de crecimiento de los mismos (Santos y Tellería, 2006). En este sentido, al ocupar pequeñas superficies, la posibilidad de proveer servicios ambientales se encuentra potencialmente reducida.

En la misma línea, pero desde otra perspectiva, la fragmentación en los espacios periurbanos es abordado por diferentes autores que rescatan la importancia de abordar estos procesos en el ordenamiento territorial (Larrazábal, Gopar-Merino y Vieyra, 2014). En este marco, los servicios ambientales de regulación de la temperatura y de absorción de agua que los ecosistemas residuales y los neoecosistemas proveen deben ser considerados en las políticas de OT (Gómez-Baggethun \& Barton, 2013). En este caso local se sancionó una normativa, sin embargo, sin una ejecución concreta la conservación de los ecosistemas no está garantizada.

\section{Conclusiones}

La identificación de los diferentes usos del suelo desde la perspectiva de las estructuras ecosistémicas presentes, permite ensayar propuestas alternativas orientadas a mejorar las condiciones de la realidad del territorio, poniendo en primer plano las deficiencias respecto a la conservación de los recursos proveedores de servicios ambientales, los cuales si no se consideran desde la normativa y gestión local, pueden conllevar a problemáticas socio ambientales.

Los ecosistemas residuales, cuentan con valores sociales y ambientales que si bien en Villa María fueron considerados por la normativa, en la práctica no hay estrategias concretas que contribuyan a su protección. Esto sin duda afecta los servicios ambientales que actualmente proveen.

La articulación entre los elementos y valoración de las estructuras ecosistémicas presentes en el espacio periurbano de una ciudad pueden no ser grandes representaciones a escalas 
mayores; sin embargo, en la escala abordada, cada parche es importante ya que el Espinal se está perdiendo por la antropización y sus funciones de provisión de servicios de regulación son de gran importancia para el ordenamiento territorial.

En este sentido, las estructuras definidas en el trabajo aporta bases para un ordenamiento territorial, la conservación de la calidad de los recursos y una posible provisión de servicios ambientales. En virtud de ello, el trabajo mancomunado con la gestión municipal de Villa María en torno a la consolidación del "Área de Ruralidad Urbana" aportará a la conservación de dichas estructuras y los servicios ambientales.

\section{Referencias Bibliográficas}

Allen, A., Dávila, J. D., y Hofmann, P. (2005). Gobernabilidad y acceso al agua y saneamiento en la interfaz periurbana: análisis preliminar de cinco estudios de caso. Cuadernos del CENDES, 22(59), 23-44.

Aramburu, M. P., Escribano, R., y Rubio, B. (2001). Cartografía del paisaje de la Comunidad de Madrid. III Congreso Forestal Español. Congreso llevado a cabo en Sierra Nevada, España.

Barsky, A. (2005). El periurbano productivo, un espacio en constante transformación. Introducción al estado del debate, con referencias al caso de Buenos Aires. Scripta Nova. Revista electrónica de Geografía y Ciencias Sociales, 9 (194), 1-36.

Bran, D., Gaitán, J. J., y Wilson, M. G. (2017). Los indicadores de calidad de suelo como un componente de la sustentabilidad de los agroecosistemas. En M. G. Wilson. (Ed.), Manual de indicadores de calidad del suelo para las ecorregiones de Argentina (pp. 15-17). Entre Ríos, Argentina: Ediciones INTA.

Breuste, J., Haase, D., \& Elmqvist, T. (2013). Urban landscapes and ecosystem services. Ecosystem services in agricultural and urban landscapes, 83-104.

Buzai, G. D., Baxendale, C. A., Humacata, L. y Principi, N. (2016). Sistemas de información geográfica. Cartografía temática y análisis espacial ampliada. Buenos Aires, Argentina: Lugar Editorial.

Cendrero A., Francés, E., Latrubesse, E. M, Prado, R., Fabbri, A., Panizza, M., Cantú, M. P., Hurtado, M., Giménez, J. E., Martinez, O., Cabral, M., Tecchi, R. A, Hamity, V., Ferman, J. L., Quintana, C., Ceccioni, A., Recatala, L., Bayer, M., y Aquino, S. (2002). Proyecto RELESA-ELANEM: Uma nova proposta motodológica de índices e indicadores para avaliaçao da qualidade ambiental. Revista Brasileira de Geomorfologia, (1), 33-47.

Di Pace, M. y Caride Bartons, H. (2012). Ecología Urbana. Buenos Aires, Argentina: Editorial UNGS.

Gómez-Baggethun, E., \& Barton, D. N. (2013). Classifying and valuing ecosystem services for urban planning. Ecological economics, 86, 235-245.

Gómez Orea, D., y Gómez Villarino A. (2013). Ordenación territorial. Mundi-Prensa Libros.

González Urruela, E. (1987). La evolución de los estudios sobre las áreas periurbanas. Anales de geografía de la Universidad Complutense, (7), 339-448.

Guimarães, R. P. (1998). Aterrizando una cometa: Indicadores territoriales de sustentabilidad. Santiago de Chile, Chile: CEPAL.

Guzmán, L. A. (2019). Evaluación de la calidad ambiental en la región de Villa María, provincia de Córdoba. Tesis Doctoral. Universidad Nacional de Río Cuarto. 
Guzmán, L.A., Castro, R., Becker, A., Furlán, M. L., y Rodríguez J.M. (2016). Delimitación de parches de uso del suelo en la zona periurbana de Villa María, Córdoba, Argentina. Revista Mapping 25 (177). 32-39.

Larrazábal A., Gopar-Merino L.F., Vieyra A. (2014) Expansión urbana y fragmentación de la cubierta del suelo en el periurbano de Morelia. Urbanización, sociedad y ambiente, 89-120

Ley Provincial No 9.509. Córdoba, 2008. Recuperado de_https://boletinoficial.cba.gov.ar/wpcontent/4p96humuzp/2014/12/040908_seccion1.p

Ley Provincial $N^{\circ}$ 7343. Principios rectores para la preservación, conservación, defensa y mejoramiento del Ambiente. Córdoba, 27 de septiembre de 1985 . Recuperado de http://web2.cba.gov.ar/web/leyes.nsf/0/49475DE2735678FC83257643005D659F?OpenDocument\&Highlight= 0 ,ambiente.

Massiris Cabeza, Á. (2005) Fundamentos conceptuales y metodológicos del ordenamiento territorial. Universidad Pedagógica y Tecnológica de Colombia, Boyacá.

Matteucci, S. D. (1998). La creciente importancia de los estudios del medio ambiente. En S. D., Matteucci y G., Buzai (Ed.), Sistemas ambientales Complejos: herramientas de análisis espacial (pp.35-62). Buenos Aires, Argentina: Ed. Eudeba.

Millennium Ecosystem Assessment, MEA. (2005). Evaluación de los ecosistemas del milenio. Recuperado de https://www.millenniumassessment.org/documents/document.439.aspx.pdf.

Ministerio de Agricultura y Ganadería de la Nación (2020). Datos Agricultura, Ganadería y Pesca. Buenos Aires, Argentina: Recuperado de: https://datos.magyp.gob.ar/dataset/estimaciones-agricolas

Ministerio de Planificación Federal, Inversión Pública y Servicios. (2008). Plan Estratégico Territorial. Recuperado de https://www.argentina.gob.ar/sites/default/files/plan_estrategico_territorial_2008__avance_i.pdf.

Morello, J., y Matteucci, S. (2001). Apropiación de ecosistemas por el crecimiento urbano: Ciudad de Buenos Aires y la Pampa ondulada argentina. Gerencia Ambiental, 8 (76), 483-502.

Morello, J. y Matteucci, S. (2000). Singularidades territoriales y problemas ambientales de un país asimétrico y terminal. Realidad Económica, (169), 72-104.

Muñoz, F. (2010). Revitalización versus rurbanización. Estrategias de política territorial en Catalunya. En M. L., Bertuzzi (Ed.), Vivir en el paisaje. Reflexiones sobre problemática urbana de la costa (pp.26-39). Santa Fe, Argentina: Ediciones UNL.

Naveh, Z., Lieberman, A. S., Sarmiento, F. O., Ghesa, A. C. M., y León, R. J. C. (2001). Ecología de paisaje. Teoría y Aplicación. Buenos Aires, Argentina: Ed. Facultad de Agronomía UBA.

Ordenanza Municipal $\mathrm{N}^{\circ}$ 7.209. Villa María, 2017. Recuperado de https://digesto.concejovillamaria.gob.ar/buscador/detalle/ordenanza/801/.

Ordenanza Municipal $\mathrm{N}^{\circ}$ 7.193. Villa María, 2017. Recuperado de https://digesto.concejovillamaria.gob.ar/buscador/detalle/ordenanza/785/.

Ordenanza Municipal $\quad N^{\circ}$ 5.929. Villa María, 2008. Recuperado de https://digesto.concejovillamaria.gob.ar/buscador/detalle/ordenanza/1229/.

Ortíz Moreno, J. A. y Vieyra Medrano, A. (2018) Periurbanización y sus efectos en el Ambiente y la Calidad de vida: Análisis en dos Localidades Socioeconómicamente Contrastantes de Morelia, Michoacán. En Vieyra, A., Méndez, Y., y Hernández, J. (Ed.), Procesos periurbanos (pp.61-88). Ciudad de México, México: Universidad Nacional Autónoma de México.

Pengue, W. A. (2009). Cuestiones económico-ambientales de las transformaciones agrícolas en las Pampas. Revista Latinoamericana de Economía: Problemas del Desarrollo, 40 (157), 137-161.

Portiansky, E L. (2013). Análisis multidimensional de imágenes digitales. Buenos Aires, Argentina: Universidad Nacional de la Plata.

Rüedi, R. S. (2016). Historia de Villa María. Villa María, Argentina: El Narval Ediciones. 
Santos, T y Tellería J.L. (2006) Pérdida y fragmentación del hábitat: efecto sobre la conservación de las especies. Revista Ecosistemas, 15 (2).

Zaar, M. H. (2011). Agricultura urbana: algunas reflexiones sobre su origen e importancia actual. Revista bibliográfica de geografía y ciencias sociales, 16 (944). doi: 10.1344/b3w.16.2011.25933

Zak, M. R., y Cabido, M. R. (2012). La Agricultura y los ecosistemas: Estado de situación. En Fonti D., Stauber J. C., Zak M. R., Cabido M., Heinzmann M., Ledesma M., Mariana A., Listoffsky A., y Weiss R. (Ed.), Hybris. Estudios interdisciplinarios sobre ambiente y producción de alimentos (pp.105-140). Argentina: Editorial de la Universidad Católica de Córdoba.

Zulaica, M. L. (2010). Transformaciones territoriales en el sector sur del periurbano marplatense: causas y consecuencias ambientales (Tesis de Doctorado en Geografía). Universidad Nacional Del Sur, Bahía Blanca, Argentina. 